DOES A MYPOALLERGENIC MILK IMPROVE SLEEP DISTURBANCE IN YOUNG INFANTS? Peter Lacey - Department of Child Life \& Health, University of Edinburgh, EH9 $1 \mathrm{UW}$ Scotland, U.K.

We report a prospective double-blind randomised cross over tria HA with a standard cows' milk protein (whey dominant) formula NAN on 67 infants $(45 \mathrm{M}, 22 \mathrm{~F})$ aged 6 weeks to 6 months. Records of sleep, crying, diarrhoea, colic, regurgitation, skin rashes and coughs and wheezing were recorded for 2 three-week periods (one on each formula) following an initial one week run-in period.

Night sleep (between 8pm and 8am) was confirmed to be less initially in the "sleep disturbed" infants compared to controls $(p<0.01)$. Sleep improved in the infants whether allocated HA or NAN first and improved throughout the 6 weeks of the trial to be no different from control infants at the end. There was no significant difference between the two groups with respect to any of the symptoms studied except that loose stools/diarrhoea were significantly increased $(p<0.01)$ on HA. 22 mothers completed the cross over design; 14 expressed a preference for the HA formula and only 8 for NAN. We cannot therefore confirm that the hypoallergenic milk (HA) improves sleep in a group of

ALLERGY PREVENTION IN CHILDREN OF PAREI, IS WITH ATOPIC DERMATITIS (AD)

12 Klaus M.Keller, Annemarie Bürgin-Wolff*, Stefan Wirth, Rainer Lippold (spn. by Otto Schofer) - Departments of Pediatrics, Universities of D-6500 Mainz,FRG, and $\mathrm{CH}-4005$ Base1, Switzerland*

The effects of 4 feeding regimes on the development of atopic dis ease and sensitization against cow's milk proteins were compared in a prospective study of 522 children with a 2 year follow-up. Healthy newborns were assigned to 4 groups: $(\mathrm{Br})$ Exclusively breast fed; $(\mathrm{Br}+\mathrm{HA})$ Breastfed and hypoallergenic formula; $(\mathrm{Br}+\mathrm{CM})$ Breastfed and cow's milk; (CM)Cow's milk. Serological investigations included IgG-, IgA- and IgE-antibodies against $4 \mathrm{CM}$-proteins interpreted by a geometrical mean titer (gmt) (Bürgin-Wolff, Eur J Ped 1980:133). Results: The percentage of children developing clinical signs of atopic disease is given in the table.

Low risk Risk:other parental allergy Risk parental AD Group $(n) \quad(n=227) \quad(n=248)$

$\mathrm{Br}+\mathrm{HA}(97) \quad 17$

$\mathrm{Br}+\mathrm{CM}(66) \quad 24$

$\begin{array}{lll}\mathrm{Br}+\mathrm{CM} & (66) & \\ \mathrm{CM} & \text { (170) } & 17\end{array}$

27

24
11
27
22

$(n=47)$

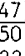

33

Gint values were highest in groups $(\mathrm{Br}+\mathrm{CM})$ and $(\mathrm{CM})$ irrespective the parental allergy- and AD-status.CM-antibodies in breastmilk were not protective.Children of parents with AD developed allergy most frequently. Feeding $\mathrm{HA}$ formula is only of limited benefit.
11 Moira Wright, Neville $R$ Belton, Neil McIntosh and designed to compare the effect of a hypoallergenic formula NANsleep disturbed infants.

ESTIMATING CEREBRAL BLOOD FLOW IN NEWBORN INFANTS: COMPARISON OF NEAR INFRARED SPECTROSCOPY AND ${ }^{133} \mathrm{XE}$-CLEARANCE.

14

iselotte skov, ole Pryds and G. Greisen Department of Neonatology, Rigshospitalet, Copenhagen, Denmark.

A new method of measuring cerebral blood flow in newborn infants by mean of near infrared spectroscopy (CBFnirs) was compared with the intravenous ${ }^{133} \mathrm{Xe}$ clearance technique (CBFXe). Forty cBFnirs measurements were obtained during 19 ${ }^{233} \mathrm{Xe}$ measurements in 16 infants. The test-retest variation of repeated NIR-measurements during each ${ }^{133} \mathrm{Xe}-\mathrm{clearance}$ was 17.58 . CBFnirs was closely related to CBFxe $\left(\mathrm{r}^{2}=0.77, \mathrm{p}<0.0001\right)$ slope $0.75 \pm$ 0.064 , intercept of $1.55 \pm 0.54 \mathrm{ml} / 100 \mathrm{~g} / \mathrm{min}$. We found the best agreement between the two We found the best agreement between the two
methods in the low range of CBF, whereas the NIRS method underestimated $\mathrm{CBF}$ in the high range of $\mathrm{CBF}$ due to methodological constrains. The NIRS method may have limitations of application in clinical research, but it has the advantage of being noninvasive and does not involve ionizing radiation.

CEREBRAL BLOOD FLOW VELOCITY IN THE HIGH RISK NEWBORN - AN INDICATOR OF EARLY PROGNOSIS

15 S. Das-Kundu, H. Bode, P. Nars Dept. of Pediatrics, University of Basel $\mathrm{CH}-4005$ Basel, Switzerland

In 175 high risk neonates $(87:>2500 \mathrm{~g}$; $50: 2500-1500 \mathrm{~g}$; $38:<1500 \mathrm{~g})$ cerebral blood flow velocities (CBFV) were measured by transcranial Doppler in the basal cerebral arteries on the 1 st, 3 rd to 5 th and 8 th to 10 th day of ife. They were compared with values of healthy neonates. Cranial ultrasound was performed on all babies. On the lst day 668 of the babies had normal, 238 decreased, and 128 increased CBFV. On day 8 to 10878 had normal, 68 decreased, and 78 increased CBFV. In babies below $1500 \mathrm{~g}$, normal CBFV were associated with the lowest incidence of cerebral hemorrhage (h) and death (d) $(6 / 23 \mathrm{~h}$; no d) while increased CBFV indicated poor prognosis $(8 / 12 \mathrm{~h} ; 7 / 12 \mathrm{~d})$. Babies with decreased CBFV showed more hemorrhages and deaths than those with normal CBFV. A similar incidence of hypoxic ischemic encephalopathies, hemorrhages and deaths was found in neonates more than $1500 \mathrm{~g}$ with both normal or abnormal CBFV. Conclusion: CBFV measured by Doppler are useful as an early prognostic parameter in infants below $2500 \mathrm{~g} \dot{\mathrm{i}} \mathrm{i} n \mathrm{~h}$ igher birth weights they may be useful for

\section{COLOR DOPPLER ECHOENCEPHALOGRAPHY}

\section{CEREBRAL BLOOD FLOW/CIRCULATION}

\section{COMPARISON BETWEEN ${ }^{133}$ XENON CLEARANCE AND OF CEREBRAL BLOOD FL.OW}

\section{H.-U. Bucher, A.D. Edwards, A.E. Lipp, G. Duc}

Neonatology University Hospital and Kinderspital Zürich, $\mathrm{CH}$

University College Hospital London, UK

Estimations of cerebral blood flow (CBF) were attempted by both ${ }^{133}$ Xe clearance and near infrared spectroscopy (NIRS) on 11 (xcasions in 9 infants (4 girls and 5 boys). The median (range) gestational age was $27(26.29)$ weeks and postnatal age was $3(1-10)$ days. All infants were receiving mechanical ventilation and cranial ultrasound or autopsy revealed that while 1 infant had no evidence of cerebral injury, 3 infants had intraparenchymal lesions, and 5 had intraventricular haemorrhage; 6 infants died.

In each study one estimation of CBF by ${ }^{13.3} \mathrm{Xe}$ was altempted; the measurement was technically inadequate in 2 cases. Withtin $1-9$ (median 5) hours 3-8 estimations by NIRS were made. $26 / 61$ measurements were technically inadequate, but at least 2 were possible in every infant. Comparisons were thus possible on 9 occasions. ${ }^{133} \mathrm{Xe}$ measurements ranged from $4.6-13.2 \mathrm{mll}(\mathrm{K}) \mathrm{g} \cdot{ }^{-1} \mathrm{~min}^{1}$ and mean NIRS measurements ranged from 8.6-20.4 mllo(x)g ' min!. The mean difference between the methods was 2.3 , and the limits of agreement were -5.0 to $+9.7 \mathrm{mll}(0) \mathrm{g} \cdot \mathrm{min}^{1}$

Considering the different principles involved and the time gap between estimations, this study shows reasonable agreement between the methods.

\section{Luca A Ramenghi, Lorenzo Quartulli, Sandra Di Fabio, Giuseppe Sabatino, (spn by Giampaolo Donzelli),
Care Unit, University of Chieti, I-66100 Chieti, Italy.} From January to December 1990, 100 color doppler echoencephalograms
were obtained in 40 infants without cardiopulmonary affections and with a mean birth weight of $2940 \mathrm{~g}$ (range $1760-3420 \mathrm{~g}$ ), a mean gestational age of 37.2 weeks (range $34-40 \mathrm{w}$ ). The examinations were performed using a
real-time $2-\mathrm{D}$ Doppler Scanner and a $3,75 \mathrm{MHz}$ sector transducer. Serial scans were obtained in sagittal, coronal and axial plans. Detection rate of intracranial vessels was: internal carotid, anterior cerebral, pericallosal, intracranial vessels was: internal carotid, anterior cerebral, pericallosal,
basilar, vertebral artery $(100 \%)$; callosomarginal artery $(90 \%)$; frontopolar basilar, vertebral artery $(100 \%)$; callosomarginal artery $(90 \%)$; frontopolar cerebral vein(GCV) and straight sinus (SS) (100\%); superior sagittal sinus $(69 \%)$; occipital sinus $(39 \%)$. Flow mean velocity of GCV and SS was 6-10 and $15-24 \mathrm{~cm} / \mathrm{sec}$ respectively. Usually vein curve has a continuous profile (therefore we can calculate only mean velocity) while sometimes, expecially in the biggest vein (SS), we observe particular aspects of vein flow similar to artery's one with a sort of systolic and diastolic phase Probably this waving venous curve is within respiratory control becouse the "squeeze" of superior cava vein may induce an increase of vein flow velocity d. ring inspiration. 